\title{
Pharmaceutical marketing of over-the-counter drugs in the current digital era: A review
}

\author{
Mohamad Saleem Anis*, Mohamed Azmi Hassali \\ Discipline of Social \& Administrative Pharmacy, School of Pharmaceutical Sciences, Universiti Sains Malaysia, Penang, Malaysia
}

\begin{abstract}
Digitization is a current era trend that has permeated various daily activities of individuals and businesses. The acceleration of digital adoption can be seen even more with the onset of the COVID-19 pandemic. As a result, a new pattern of pharmaceutical marketing has been defined in the industry in several terms, most notably pharmaceutical digital marketing (PDM). Undeniably, over-the-counter (OTC) drugs, which are pharmaceuticals sold without a medical prescription, are the most affected drug category by this digital transformation in the pharma industry. The content of this review paper is based on secondary data derived from recent literature and Internet sources. The relevant information from various journal articles, books, reports, and reliable web pages has been presented and discussed. Basically, the main body of the review was divided into two fundamental areas of PDM, with a greater emphasis on the context of OTC drugs: (1) online pharmacies (e-commerce marketing); (2) promotional advertising. In a nutshell, this review provides valuable insights into the emerging concepts of PDM within the scope of OTC drugs.
\end{abstract}

\section{Keywords:}

Pharmaceutical marketing, Online pharmacies, Digital marketing, OTC drugs, Non-prescription medicines

\section{INTRODUCTION}

In today's digital age, where the Internet is booming and permeating the various activities of companies and consumers across the globe, this has resulted in a profound transformation in marketing strategies and tools ${ }^{1}$. Today, digital marketing is more than just a subtype of conventional marketing; it is a new phenomenon that plays an effective role in achieving marketing goals ${ }^{2}$. The spread of digital marketing is due to several advantages from marketers' perspective, the most important of which are: ease of targeting customers with high accuracy, costeffectiveness, and global reach ${ }^{3}$. Despite the noticeable differences between marketing in the pharmaceutical sector and other industries because of the special conditions of pharmaceutical products in comparison to other commercial products, from the theoretical perspective, pharmaceutical marketing shares the same principles as marketing science. It can be considered one of its subsets ${ }^{4}$. Moreover, many companies in the pharmaceutical industry consider the advertising and marketing department as one of their indispensable cornerstones due to its ability to contribute to business sustainability and generates sales in the short and long term ${ }^{5}$. Fischer and his colleague noted that it is surprising for many that pharmaceutical firms are among the highest spenders on marketing, with a marketing spend-to-sales that ratio may be as high as $30 \%{ }^{6}$. In fact, the type of pharmaceutical product has a significant impact on the marketing strategy chosen.

Despite significant limitations on direct marketing of pharmaceutical products to the public, there is a category of drugs that allows the companies the freedom to advertise. These drugs, known as over-the-counter (OTC) or non-prescription drugs, can be purchased directly from pharmacies without needing a medical prescription. Unfortunately, although the market for OTC drugs is highly competitive, most pharmaceutical marketing studies have focused on prescription drugs ${ }^{7}$.

However, OTC drugs marketers should not consider physicians as their main target segment. Although physicians are knowledgeable regarding this category of products; they lack the authority to make

\section{*Corresponding author:}

*Mohamad Saleem Anis Email: saleem@student.usm.com, saleem.anees@yahoo.com 
recommendations. Therefore, customers are the primary target of OTC marketers because they have the power to make decision ${ }^{8}$. This has provided many pharmaceutical marketers with the opportunity to leverage various tools and solutions in digital marketing and initiate the development of a new marketing approach known as pharmaceutical digital marketing (PDM), which can target either physicians or consumers ${ }^{9}$. Pharmaceutical marketers did not only create online advertising campaigns, including social media platforms, but they also went so far as to sell medicines directly to consumers, such as through online pharmacies (or e-Pharmacies). They would be able to provide convenience and efficiency, as well as a unique healthcare experience for the consumers, if they used proper e-commerce marketing tactics $^{10}$. It is no secret that the COVID-19 outbreak has catalyzed the role of PDM in the market for OTC drugs by contributing to the massive transformation of people as individuals and businesses to virtual modes of communication $^{11}$. Many people have taken multiple types of these drugs to boost their immunity to the virus and alleviate its symptoms ${ }^{12}$. The previous literature on PDM has been presented in this review paper, although it is still in its infancy. Thus this field has yet to be adequately studied.

\section{OVERVIEW OF PDM}

Rapid technological developments contribute to creating a fertile digital environment, which has resulted in the emergence and growth of a modern marketing method known as digital marketing ${ }^{13}$. Kotler and his colleagues defined digital marketing as "what a company does to publicize, promote, and sell products and services on the Internet" ${ }^{14}$. Therefore, one-way online communication (known as "Web 1.0" or "readonly") is no longer available, and digital marketing was not unique enough because it did not differ significantly from traditional marketing, such as newspaper or television advertising. Since the emergence of Web 2.0, which have become fully interactive, digital marketing methods have also evolved to the next level ${ }^{15}$, as organizations at the managerial level recognize the need to modify business models and find a new way to fully exploit digital potential as part of multi-channel marketing $^{16}$, and thus increase their market competitiveness ${ }^{17}$.

Over the years, with the advancement of technology, the pharmaceutical industry has also jumped on board with the goal of maximizing profits in one of the most challenging market ${ }^{18}$. Although no single agreedupon definition of PDM exists, the definition of digital marketing, also known as electronic marketing, online marketing, Internet marketing, or web marketing, can easily be adapted to create an appropriate one for it as follows: "PDM is a set of strategies and tactics that are designed by pharmaceutical enterprises and executed through digital channels to achieve their objectives (often to increase shareholder profits) within a specific time and budget". The author developed this definition based on Minculete and Olar's definition of digital marketing ${ }^{19}$. Although digital marketing is superior to traditional marketing because it is a less time-consuming and costeffective way of communicating with consumers, it still faces some challenges in the pharmaceutical industry ${ }^{20}$. The following are some of the most significant of these challenges: 1. there is inadequate and lack of good vision in the sector for implementing digital marketing solutions; 2 . there is also a lack of workforce with digital minds; and 3. there are strict regulations that require each digital campaign to be carefully examined ${ }^{20-21}$. On the other hand, pharmaceutical companies would not stand idly by as they work hard to sharpen their digital skills and transition to new technologies to catch up with a large portion of their customers who are already involved in this space ${ }^{22}$. According to Parekh et al., pharmaceutical companies develop and implement proper and comprehensive marketing strategies to make, digitalization soon become the industry's backbone ${ }^{20}$. Indeed, PDM has the potential to be a unique tool that propels brands in the pharmaceutical industry forward by transforming how they communicate with consumers and increasing transparency and engagement ${ }^{23}$. It is also crucial to recognize that digitalization is inevitable and will determine how the brand is perceived in the market in the near future ${ }^{22}$. Unsurprisingly, the digital paradigm shift has also influenced direct-to-customer advertising (DTCA) in the pharmaceutical industry, giving rise to a new generation known as DTCA 2.0, which employs new interactive web tools such as websites and social media sites (Facebook, Twitter, and YouTube) ${ }^{24}$. Indeed, with millions of users browsing these platforms worldwide, DTCA 2.0 has become a highly powerful marketing tactic that cannot be ignored ${ }^{25}$. Moreover, it is no longer limited by geographical boundaries ${ }^{26}$.

Furthermore, OTC drugs are the key beneficiary of these emerging digital marketing tactics in the pharmaceutical industry. It could be argued that digital marketing has become one of the vital influences on consumers' purchasing decisions for OTC products in recent years ${ }^{27}$. This is because these drugs are similar to daily consumables, in the sense that consumers can usually choose what they want freely ${ }^{28}$. Moreover, with the advent of modern technological tools and an increasingly savvy consumer population, they go beyond reading the label of the OTC medicine package, They can access the product information and make decisions during the purchase process using the internet, smartphones, applications, two-dimensional (2D) barcodes, etc ${ }^{29}$.

\section{TYPES, CHANNELS, AND TOOLS OF PDM}

Nowadays, consumers are inextricably linked 
to the internet and conduct their healthcare research ${ }^{30}$. Pharmaceutical companies, in turn, should keep track of what their consumers are doing and have access to the same places where their consumers are at the right time, as well as adopt a more flexible organizational structure and revised business plan to keep up with advanced marketing tools and technological innovations ${ }^{31}$. These internet-related innovations are becoming highly involved in pharmaceutical marketing management across the industry, and they started to change some aspects of the traditional environment of OTC drug marketing approaches ${ }^{32}$. All of this leads to an increase in the use of OTC products due to their ease of access and reasonable cost, which enhances the value of its market as a more viable business.

On the other hand, several academic voices are concerned about misleading consumer marketing of OTC drugs. Ryvak and Denysiuk, for instance, stated that the marketing of OTC drugs should adhere to socially responsible principles such as providing patients with reliable information regarding all potential negative consequences of irresponsible self-medication ${ }^{33}$. Advertisements of OTC products, including online ads, usually approach the problem from a single point of view due to their short nature. In some cases, the patient's lack of information before purchasing the OTC drug may result in a misunderstanding of the actual health condition or delayed intervention by a healthcare professional ${ }^{34}$.

In fact, because of the changes and updates that occur regularly in their tools, channels, and platforms, it is almost impossible to have a comprehensive and consistent classification of digital marketing types used in the pharmaceutical market, as it is with most theoretical concepts that are still in the early stages of development of their components. The areas of digital marketing have been divided into two main categories based on a holistic view of current digital marketing components: marketing related to e-commerce, which falls under the activities of online pharmacies, and marketing related to promotional and advertising goals, which is conducted via digital platforms (Figure 1).

\subsection{PDM and online pharmacies (e-commerce mar- keting)}

Following a period of e-commerce innovation that resulted in the emergence of e-commerce marketing as a term during the last period, which can be defined as the act of driving awareness and action toward a website that is used as a platform to sell products or services electronically ${ }^{35}$. Many pharmaceutical companies and other businesses, such as physical drugstores, were quick to capitalize on the opportunity by establishing their own platforms, the online pharmacies, also known as epharmacies, internet pharmacies, or mail-order pharmacies, to generate a new source of revenue from product

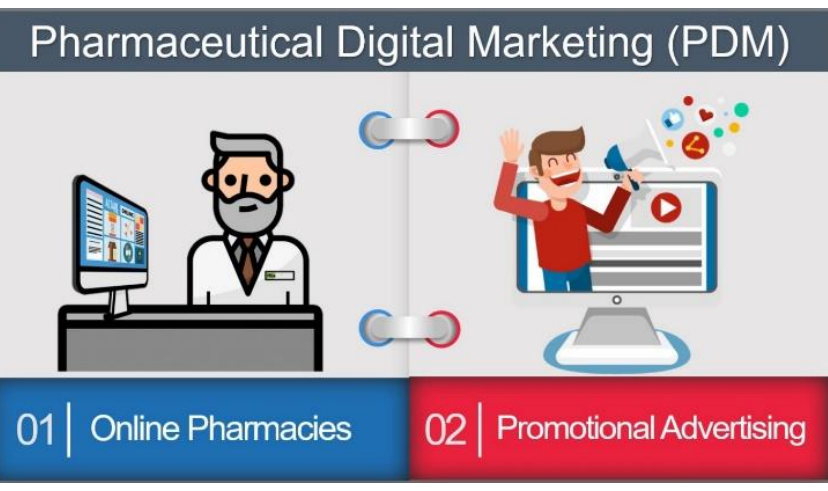

Figure 1. Pharmaceutical Digital Marketing Categories.

sales. This new pharmacy pattern is an online service that allows consumers to access online drugs and then delivers them to patients via various shipping channels. Health and pharmaceutical products have become one of the most popular product categories on e-commerce websites. For instance, according to one study conducted in Germany, $61 \%$ of Internet users have purchased medicines through online pharmacies, with $73 \%$ of these medicines being in the non-prescriptions (OTC) category $^{36}$. In 2008, the same country achieved the highest rate in the world in terms of the proportion of online sales as a percentage of total OTC medicines sales, surpassing $17 \%$ from $6.4 \%{ }^{28}$. In the United States (U.S.), the e-commerce sales value of pharmaceuticals and beauty aids has risen year-over-year, reaching 35.7 billion U.S. dollars in $2017^{37}$. Another example comes from Amazon, a major player in the retail e-commerce business, where healthcare and beauty products are expected to achieve the highest sales growth change in 2019 with a percentage of $28^{38}$. As an ambitious global competitor in this promising sub-industry, Amazon not only distributed OTC drugs to specialized pharmaceutical companies, but also began to expand its business by developing and marketing OTC products of its own in the form of exclusive brands in late $2017^{28}$. It can be inferred that the trading of some pharmaceutical products, specifically OTC drugs, is not limited to being exclusively affiliated with online pharmacies of pharmaceutical companies or licensed physical pharmacies. At the same time, the leading multi-vendor marketplace sites such as Amazon, Ali Baba, and Lazada have their own market share as emerging players in this field, based on their high level of efficiency, credibility, and visibility by potential buyers.

The expected growth of the Internet retailing (e-commerce) of OTC products can be recognized because it is currently the fastest-growing distribution channel worldwide, with consumers increasingly shifting toward using digital platforms that provide convenience, delivery, and 24/7 accessibility ${ }^{39}$. One of the primary determinants for consumers to purchase OTC drugs online is the ability to save their valuable time ${ }^{40}$. For in-stance, almost half of the consumers polled in the 
Czech Republic preferred purchasing OTC drugs from online pharmacies because they can place orders from the comfort of their own home, hence saving time ${ }^{41}$. However, during his research, a Finnish scholar discovered several barriers to purchasing OTC medicines online, including high delivery costs, a long delivery period, a lack of additional value, and the acute nature of the pathological symptoms ${ }^{42}$.

Furthermore, in terms of segmenting the global online pharmacy market by region in 2018, North America is at the forefront due to a tech-savvy community base and the government's efforts to raise awareness regarding illegal online drugstores. The Asia-Pacific market has also witnessed significant growth, fueled by the increasing burden of chronic diseases and a growing number of senior populations. The high cost of treatment has shifted user preferences toward online services that offer lucrative deals ${ }^{43}$. One research attempted to analyze the situation in India, a developing country, and discovered a high potential for the growth of the online pharmacy market due to several enablers, the most important of which are: increased internet penetration in the country, low prices of smartphones and data rates, aging population, and rising spending power ${ }^{44}$. Overall, the global online pharmacy market is expanding substantially, with a value of around $\$ 42.32$ billion in 2018 and a projected value of $\$ 107.53$ billion by $2025^{43}$.

Nevertheless, certain challenges continue to impede this emerging business, and more attention is required to address or minimize them. These challenges include: trust, ordering, and customer support issues such as timely delivery, accessibility of remote parts of cities, language barrier, and user data privacy ${ }^{44}$. However, suppose all stakeholders are fully aware that the online pharmacy business model is a golden opportunity to create a win-win situation for everyone in the value chain (including consumers, local pharmacies, pharmaceutical companies, and governments). In that case they will strive to mitigate those challenges. Considering all of the facts above, market competition will definitely increase to a new level in an attempt to gain consumer satisfaction and loyalty, where enhancing user experience can differentiate one platform from another. Moreover, to make it more organized and controlled, many governments worldwide have begun to take a position to regulate some emerging online sales platforms that may affect the health of their citizens. After the most recent legal changes in Romania in 2018, for example, the green light for the online sale of OTC drugs through licensed pharmacies' websites was officially given in all Central European countries ${ }^{45}$.

Finally, the adoption of various e-business models will not stop anytime soon with the goal of taking holistic advantage of it in all aspects of this sector. Based on the previous facts, in the context of online pharmacies and considering their increasing number, and thus the competition among them, they should use some digital marketing tools that are upgraded periodically, both free and paid types. These tools are specialized in raising visibility, strengthening the quality of visitors, and promoting those websites provided they are used in accordance with appropriate strategies. Digital marketing can be considered the fastest e-commerce solution available in the market ${ }^{46}$. In the context of the social order, which is referred to as online orders through social media platforms, Facebook plays a powerful role in the health and beauty industry while it shows a marked control of the market by $81 \%{ }^{47}$. In addition to essential digital marketing tools, online pharmacies, like an e-commerce business model, should consider the latest technological innovations in the market and take advantage of real-time data collection and use them as a competitive advantage by gaining a better understanding of their consumers and enhancing their consumers the shopping experience. These technologies, such as machine learning systems (MLS), are a subset of artificial intelligence (AI). They are fed with large amounts of data in order to generate related decisions that can be adopted by online pharmacy marketers. For instance, MLS assists in identifying patterns based on purchase history, account information, browsing, etc. Then it creates customized recommendations for each consumer using the websites ${ }^{48}$. At the same time, augmented reality (AR) can be uniquely helpful for the geo-localization of the online pharmacy products directly on the shelf, barcodes, navigation, etc ${ }^{47}$.

\subsection{PDM and promotional advertising}

A concept called business to business to consumer (B2B2C) marketing approach is one of the distinctive bases that emphasizes the uniqueness of marketing in the pharmaceutical industry. While the traditional strategy was based on a focus in the first part of the concept (B2B), pharmaceutical companies were almost completely oriented towards marketing to physicians or pharmacists, who convinced the latter part (Business to Consumer, B2C), the patients and consumers, and helped them to make the best purchase decision ${ }^{49}$. However, with the growing role of non-prescription OTC medications and the revolution of the next internet generation and new-age digital technologies, including digital marketing tools with smart targeting and costeffectiveness features ${ }^{46}$, pharmaceutical companies and retail pharmacy chains are beginning to realize that a new window has opened for them to spend some of their marketing budgets to target the end consumers directly. Obviously, the cost of launching an online marketing campaign is much lower than the cost of placing an advertisement on a TV channel or a billboard. The cost of establishing a virtual presence for an OTC brand and interacting with consumers via digital means is 
significantly lower ${ }^{50}$. For example, medical diagnostic laboratories' advertising spending in the U.S. increased from $\$ 75.4$ million to $\$ 82.6$ million between 1997 and 2016, despite the fact that the number of advertisements increased significantly (from 14,100 to 255,300 ), reflecting the increased implementation of affordable online advertising techniques ${ }^{51}$. Besides, digital marketing enables businesses to become more cost-effective by measuring and improving the return on investment (ROI) of their advertising campaigns ${ }^{52}$. Consequently, pharma organizations are maneuvering to cope with the market changes, particularly the OTC drug market, through enabling a digital mindset and culture across the entire organization. In line with such initiatives adopted to implement digital action plans in the industry, Johnson \& Johnson has declared that more than 50\% of its marketing is now digital marketing ${ }^{53}$. Fortunately, preliminary indications of consumer interaction with online pharmaceutical advertising initiatives have been positive. For instance, according to a Comscore survey of 163 pharmaceutical studies, $51 \%$ of the pharma advertisements were viewable, and thus pharmaceutical advertising impressions had the highest viewability rate among the other ten industries benchmarked by the study ${ }^{54}$. Moreover, effective online public relations can play a vital role in developing an OTC brand reputation. Vicks DayQuil and NyQuil, as an example of a successful OTC drug Facebook page with nearly a million followers, has celebrated its accomplishments by posting how the brand was named the most trusted cold and flu medicine in the U.S. by Reader's Digest. Another effective strategy is to form a partnership with celebrities. For instance, in 2016, Claritin announced its partnership with Kelly Rowland as its spokesperson, which resulted in a lot of earned media for the brand that year ${ }^{55}$.

Over the last two decades, many modern means, tools, and channels have been created and evolved continuously to enable companies or individuals to conduct digital marketing activities, leading to critical changes in business logic and consumers' behavior. Indeed, these tools come with features that no one could have imagined in the last decade of the $20^{\text {th }}$ century to identify, attract, engage, and increase loyalty. The importance of this emerging marketing strategy is to create many unparalleled opportunities that are compatible with today's digital age by reaching the right people, in the right place, at the right time as well as leveraging the digital channels to connect with current and prospective consumers ${ }^{56}$. In addition, one of the major benefits of conducting digital campaigns is the flexibility to track and monitor the results of the marketing campaign in real-time with the ability to view customer response rates and measure marketing success straightaway rather than conducting costly market research. In short, the main benefits of the spectrum of digital marketing tactics can be summarized as follows: cost-efficient, better expo- sure, time-saving, targeting, new products or services awareness, consumer engagement campaigns, customer personalization, and last but not least, brand building ${ }^{23,46}$.

Besides, although many types and channels are available to marketers to assist them in designing and implementing customizable digital advertising, they must build integrated professional marketing strategies through a comprehensive mixing of different marketing methods. A methodology combining traditional offline marketing with free and paid digital marketing tools should be developed to achieve the organization's carefully set objectives in line with its short and long-term vision. Search engine marketing (SEM), social media marketing (SMM), affiliate marketing, content marketing, email marketing, mobile marketing, display advertising, re-marketing, video advertising, influencer marketing, online brochures, inbound marketing, webinars, e-detailing, and medical portals are some examples of digital marketing types that pharmaceutical companies can use ${ }^{19,22,46,56-57}$. Additionally, even though pharmaceutical companies that produce OTC drugs can now engage more with their consumers through many touchpoints, mobile apps are indisputably one unique digital marketing tool. Consumers have become more interested in tracking their health using health applications. Sixtyone percent of American consumers have reported that they have installed a mobile health application. Although there are many healthcare applications in the market, however, a very small number of OTC brands have released applications to support the purchase process. For instance, out of the 100 top OTC brands, only 3 OTC brand applications existed in the app store in 2017. Therefore, pharma companies have a unique opportunity to develop a distinctive brand experience by introducing their own application ${ }^{55}$. Indeed, in all cases, the company's or OTC brand's official website remains a key digital asset in most digital marketing activities and the channel that most of its approaches lead to, where it is useful both as a starting spot and as a destination ${ }^{19}$.

\section{CONCLUSIONS}

Digital marketing is being embraced faster by all sectors, especially with the global impact of the novel COVID-19 pandemic. The large and growing number of existing or potential consumers who use and communicate via digital platforms is creating new opportunities for digital marketers to attract and retain these consumers ${ }^{56}$. Pharmaceutical marketing strategies, in turn, seem to be experiencing some drastic changes towards digitalization, particularly for OTC drugs. PDM of OTC products is typically used by pharmaceutical companies to target the patients or final consumers, where direct advertising to them is also considered important for the reputation of companies in the market and the empowerment of their OTC brands ${ }^{58}$. In contrast to prescription 
drugs, the main advantage of this drug category is that its marketing practices are, in most cases, semirestricted. To conclude, with all of its marketing and ecommerce channels, the digital age has opened a new door for more efficient promotion or even sales of OTC drugs online. Unfortunately, in light of a challenging environment with many rapidly evolving digital platforms, this emerging type of pharmaceutical marketing is still new and immature. Hence, marketing experts from all over the world who specialize in PDM dominance are needed to periodically develop and test the best practices and strategies that can be effectively applied to the unique OTC drug market. These new strategies should be integrated with traditional marketing efforts to achieve high consumer satisfaction and optimal investment returns.

\section{ACKNOWLEDGEMENT}

For this paper, we don't have a scholarship or grant supporter.

\section{Conflict of interest}

There is no conflict of interest.

\section{Funding}

None to declare.

\section{Ethics approval}

None to declare.

\section{Article info:}

Received June 15, 2021

Received in revised form November 6, 2021

Accepted December 22, 2021

\section{REFERENCES}

1. Krishnamurthy S. Contemporary Research in E-marketing. University of Washington, USA: IGI Global; 2005.

2. Piñeiro-Otero $T$, Martínez-Rolán X. Understanding digital marketing-basics and actions. Cham: Springer; 2016. p. 37-74.

3. Goel R, Sahai S, Krishnan C, Singh G, Bajpai C, Malik P. An Empirical Study to Enquire the Effectiveness of Digital Marketing in the Challenging Age with Reference to Indian Economy. Pertanika J Soc Sci. 2017;25(4):1569-84.

4. Anderson E, Coughlan AT. International market entry and expansion via independent or integrated channels of distribution. J Mark. 1987;51(1):71-82.

5. Mohammadzadeh M, Aarabi SM, Salamzadeh J. Organizational performance, Marketing strategy, and Financial strategic alignment: an empirical study on Iranian pharmaceutical firms. DARU. 2013;21(1):65.

6. Fischer M. Marketing spending models. Innovation and Marketing in the Pharmaceutical Industry. New York: Springer; 2014. p. 557-89.

7. DeLorme DE, Huh J, Reid LN, An S. The state of public research on over-the-counter drug advertising. Int J Pharm Healthc Mark. 2010;4(3):208-31.

8. Rollins BL, Perri M. Pharmaceutical marketing. Burlington, USA: Jones \& Bartlett Publishers; 2014.
9. Jawaid M, Ahmed SJ. Pharmaceutical Digital Marketing and Its Impact on Healthcare Physicians of Pakistan: A National Survey. Cureus. 2018;10(6):e2789.

10. Chaturvedi AK, Singh UK, Kumar A. Online pharmacy: An estrategy for medication. Int J Pharm Front Res. 2011;1(1):146-58.

11. Alyahya M, Dhruvakumar S, Siddegowda SH, Sreeharsha N. Impacts of digital marketing on the pharmacies community in saudi arabia and determining the future model of the industry: A cross-sectional questionnaire-based study. Indian J Pharm Educ Res. 2020;54(4):1193-206.

12. Tomar H. Post-COVID Emergent Trends in Consumer Buying Behaviour for Pharma-OTC Sector. NMIMS Mumbai; 2021.

13. López García JJ, Lizcano D, Ramos CM, Matos N. Digital marketing actions that achieve a better attraction and loyalty of users: An analytical study. Future Internet. 2019;11(6):130.

14. Kotler P, Shalowitz JI, Stevens RJ. Strategic Marketing for Health Care Organizations: Building a Customer-Driven Health System. New York: John Wiley \& Sons; 2008.

15. Liang BA, Mackey TK. Prevalence and global health implications of social media in direct-to-consumer drug advertising. J Med Internet Res. 2011;13(3):e64.

16. Roblek V, Bach MP, Meško M, Bertoncelj A. To click or to buy over the counter drugs: exploring the behaviour of Slovenian customers. Int J Electron Mark Retail. 2018;9(2):145-66.

17. Siglioccolo M, Perano M, Siano A, Pellicano M, Baxter I. Exploring services provided by top Italian museums websites: what are they used for?. Int J Electron Mark Retail. 2016;7(4):141-58.

18. UKEssays. Evolution of marketing techniques in pharmaceutical industry [document on the Internet]. 2018 [cited 2021 Sep 12]. Available from: https://www.ukessays.com/essays/marketing/ evolution-of-marketing-techniques-in-pharmaceutical-industrymarketing-essay.php?vref=1.

19. Minculete G, Olar P. Approaches to the Modern Concept of Digital Marketing: Proceedings of the $21^{\text {st }}$ International conference of The Knowledge-Based Organization. Sciendo; 2018; 24(2):63-9.

20. Parekh D, Kapupara P, Shah K. Digital Pharmaceutical Marketing: A Review. Res J Pharm Technol. 2016;9(1):108-12.

21. Rubin M, Heskett C, Sgarro A. Unlocking Digital Marketing Opportunities for the Pharmaceuticals Sector: Avoiding the Pitfalls of Digital Marketing Implementation. London, England: L.E.K. Consulting; 2012.

22. Bhole L, Verma S. Digital Marketing: A Road Ahead To Pharmaceutical Selling: Proceedings of the $2^{\text {nd }}$ International Conference on 'Innovative Business Practices and Sustainability in VUCA World'; Mumbai, India: IOSR Journal of Business and Management; 2018. p. 61-5.

23. Iyer A. Digital Marketing in the Pharmaceutical Industry [document on the Internet]. 2019 [cited 2020 Mar 15]. Available from: https://www.anandriyer.com/digital-marketing-in-pharmaceuticalindustry/.

24. Liang BA, Mackey TK. Online availability and safety of drugs in shortage: a descriptive study of internet vendor characteristics. J Med Internet Res. 2012;14(1):e27.

25. Mackey T, Liang B. Globalization, evolution and emergence of direct-to-consumer advertising: are emerging markets the next pharmaceutical marketing frontier. J Commer Biotechnol. 2012; 18:58-64.

26. Applbaum K. Pharmaceutical marketing and the invention of the medical consumer. PLoS Medicine. 2006;3(4):e189.

27. Naik P. Digital Media Impact in Promotion of Over the Counter Medicines. JASRAE. 2019;16(1):2567-70.

28. Sakai M. OTC Drugs Becoming More Like Consumer Goods. Tokyo: Mitsui \& Co. Global Strategic Studies Institute; 2019.

29. Consumer Healthcare Products Association. The Future of SelfCare: OTC Medicine Outlook [document on the Internet]. CHPA; 2013 [cited 2021 Sep 29]. Available from: https://www. chpa.org/about-consumer-healthcare/research-data/researchreports/understanding-trust-otc-medicines-consumer. 
30. Memisoglu M. Branding of prescription and non-prescription drugs. Acta Pharm Sci. 2018;56(1):21-36.

31. Autry CW, Goldsby TJ, Bell JE. Global macrotrends and their impact on supply chain management: Strategies for gaining competitive advantage. New Jersey: Pearson Education; 2013.

32. Roblek V. Impact of Internet and Social Media on Organizational Change of OTC Medicines Marketing Management. Int J Electron Mark Retail. 2015;6(3):239-58.

33. Ryvak T, Denysiuk O. Public opinion study on the role of advertising in choice of non-prescription drugs for self-treatment. Pharmacia. 2019;66(3):135-40.

34. Major C, Vincze Z. Consumer habits and interests regarding non-prescription medications in Hungary. Fam Pract. 2010;27 (3):333-8.

35. Perricone C. Everything You Need to Know About Ecommerce Marketing [document on the Internet]. HubSpot, Inc.; 2020 [cited 2020 Mar 15]. Available from: https://blog.hubspot.com/marketing/ecommerce-marketing.

36. Davies J. Amazonising pharmacy-reality or just a rumour? [document on the Internet]. Royal Pharmaceutical Society; 2017 [cited 2021 Sep 29]. Available from: https://pharmaceuticaljournal.com/article/opinion/amazonising-pharmacy-reality-orjust-a-rumour.

37. Clement J. U.S. online shop and mail-order sales of drugs, health and beauty aids 2003-2017 [document on the Internet]. Statista; 2019 [cited 2020 Mar 15]. Available from: https://www.statista. $\mathrm{com} / \mathrm{statistics} / 185452 / \mathrm{us}$-online-shops-and-mail-order-housessales-figures-for-pharmaceuticals/.

38. Koch L. Did 'Clicks' Really Surpass 'Bricks' for Share of US Retail Sales? Not Exactly [document on the Internet]. eMarketer; 2019 [cited 2020 Mar 15]. Available from: https://www.emarketer.com/content/did-clicks-really-surpass-bricks-for-share-ofus-retail-sales-not-exactly.

39. Roberts K. Market Research Blog [document on the Internet]. Euromonitor; 2018 [cited 2020 Apr 04]. Available from: https:// blog.euromonitor.com/otcs-e-commerce/.

40. Hawkins D, Coney K, Best R, Hawkins D. Consumer behavior: Building marketing strategy. New York: Mcgraw-Hill College; 2003.

41. Lostakova H, Curdova M, Janouch V. Purchace Behavior of Online Pharmacies Clients. Ekon Vadyb. 2012;17(1):1-9.

42. Punakivi K. Acceptance and use of online pharmacies and the online customer journey for the purchase of OTC medicines. Master [dissertation]. Helsinki: University of Helsinki; 2019.

43. Zion Market Research. Global E-Pharmacy Market Is Expected To Reach Around USD 107.53 Billion By 2025 [document on the Internet]. 2019 [cited 2020 Mar 16]. Available from: https:// www.zionmarketresearch.com/news/e-pharmacy-market.

44. Madan A, Mehta J, Kumar A. e-pharma: delivering healthier outcomes. India: Ernst \& Young LLP; 2019.

45. PMR Report. Online sales of OTC drugs legal throughout
Central Europe. PMR Healthcare Market Experts [document on the Internet]. 2019 [cited 2020 Mar 16]. Available from: https:// healthcaremarketexperts.com/en/news/pmr-report-online-salesof-otc-drugs-legal-throughout-central-europe/.

46. Shirisha M. Digital Marketing Importance in the New Era. Int J Eng Technol Sci Res. 2018;5(1):612-7.

47. Vagnozzi E. Sales online of Health Products: Economical and Administrative Perspective [document on the Internet]. 2015 [cited 2020 Mar 16]. Available from: http://amsacta.unibo.it/ 4242/1/Sales_online_of_health_products.pdf

48. Shyna K, Vishal M. A Study on Artificial Intelligence in ECommerce. Int J Adv Eng Sci Res. 2017;4(4):62-8.

49. Powell G. The Challenges Of B2B2C Marketing In Major Corporations [document on the Internet]. Forbes; 2018 [cited 2020 Mar 16]. Available from: https://www.forbes.com/sites/ forbescommunicationscouncil/2018/05/18/the-challenges-ofb2b2c-marketing-in-major-corporations/.

50. Bostanshirin S, editor. Online marketing: Challenges and Opportunities: Proceedings of SOCIOINT14-International Conference on Social Sciences and Humanities; 8-10 September; Istanbul; 2014.

51. Schwartz LM, Woloshin S. Medical Marketing in the United States, 1997-2016. JAMA. 2019;321(1):80-96.

52. Bala M, Verma D. A Critical Review of Digital Marketing. IJMIE. 2018;8(10):321-39.

53. Orsini P. US Healthcare and Pharma Industry StatPack 2018 [document on the Internet]. eMarketer inc.; 2018 [cited 2020 Mar 16]. Available from: https://www.emarketer.com/content/ us-healthcare-and-pharma-industry-statpack-2018.

54. Comscore. New Pharma Digital Marketing Benchmarks Show that Online Pharmaceutical Marketing Continues to Drive Brand Awareness, Favorability and Conversions [document on the Internet]. 2014 [cited 2020 Mar 17]. Available from: https://www. comscore.com/Insights/Press-Releases/2014/7/New-Pharma-Digital-Marketing-Benchmarks-Show-that-Online-PharmaceuticalMarketing-Continues-to-Drive-Brand-Awareness-Favorabilityand-Conversions.

55. IRI, Kline. OTCs ONLINE: The impact of e-commerce and digital presence on OTC brands [document on the Internet]. Kline Group; 2018 [cited 2020 Mar 17]. Available from: https://www. klinegroup.com/wp-content/uploads/2018/12/Digital_OTCs.pdf.

56. Alexander L. The Who, What, Why, \& How of Digital Marketing [document on the Internet]. HubSpot, Inc.; 2020 [cited 2020 Mar 17]. Available from: https://blog.hubspot.com/marketing/what-is-digital-marketing.

57. Istvanic M, Crnjac Milic D, Krpic Z. Digital marketing in the business environment. Int J Electr Comput Eng Syst. 2017;8(2): 67-75.

58. Vats S. Impact of direct to consumer advertising through interactive internet media on working youth. Int J Bus Adm Res Rev. 2014;1(2):88-99. 